\title{
Neuroretinitis causada por Bartonella Henselae
}

\section{Neuroretinitis caused by Bartonella Henselae}

\author{
Jairo Hernández Pinzón ${ }^{1}$ Maximiliano Darakdjian ${ }^{1}$ \\ ${ }^{1}$ Departamento de Diagnóstico por Imágenes, Fleni, Buenos Aires, \\ Argentina
}

Rev Argent Radiol 2020;84:133-135.

Estimados editores,

El género Bartonella, perteneciente al subgrupo alfa-2 de las proteobacterias, incluye actualmente 35 especies, al menos siete de ellas son causantes de enfermedad en seres humanos. Se trata de las Grahamii, Bacilliformis, Quintana, Elizabethae, Vinsonii, Koehleraey Henseleae, esa última con un comportamiento intracelular facultativo, de lento crecimiento y difícil cultivo, se destaca por ser causante de la enfermedad por arañazo de gato. Se calculan 12.500 pacientes diagnosticados anualmente con enfermedad por arañazo de gato, aproximadamente 550 de ellos con compromiso ocular concomitante (datos epidemiológicos de los Estados Unidos). ${ }^{1-4}$

Entre las especies que causan compromiso ocular, se han reportado B. Henseleae, B. Quintana, B. Elizabethaey B. Grahamiii. $^{2}$ El ojo es el órgano no linfático más frecuente afectado por B. Henseleae. ${ }^{3,5}$ Se reporta frecuentemente como manifestación de esa infección, el síndrome oculoglandular de Parinaud (enrojecimiento ocular, sensación de cuerpo extraño, epífora y linfadenopatías preauriculares,

\author{
Laura Falcón ${ }^{1}$
}

Address for correspondence Jairo Hernández Pinzón, MD, MSc. (e-mail: jahernandezpinzon@gmail.com).

submandibulares o cervicales), neuroretinitis, papillitis y neuritis óptica. ${ }^{6,7}$ Sin embargo, es escasa la iconografía en resonancia magnética (RM) de esa patología.

Por lo anterior, queremos compartir el caso de un paciente masculino de 38 años de edad con diagnóstico serológico de $B$. Henseleae, que consultó en nuestra institución por cuadrantopsia, metamorfopsia y edema de papila temporal en ojo derecho, y a quien se le realizó una RM de órbitas con contraste endovenoso, la cual mostró irregularidad en el polo posterior del globo ocular derecho asociado a señal hipointensa en secuencias ponderadas en T2/GRE y refuerzo patológico luego del contraste endovenoso (-Fig. 1).

La B. Henseleae invade el endotelio vascular, produciendo alteración en los mediadores trombogénicos, vasculitis obliterante y obstrucción de la arteria retiniana u oclusión venosa con afección de la cabeza del nervio óptico, lo que conlleva a inflamación masiva y alteración en la permeabilidad capilar. ${ }^{8}$ Eso puede manifestarse en RM como realce en un segmento corto del nervio óptico, con
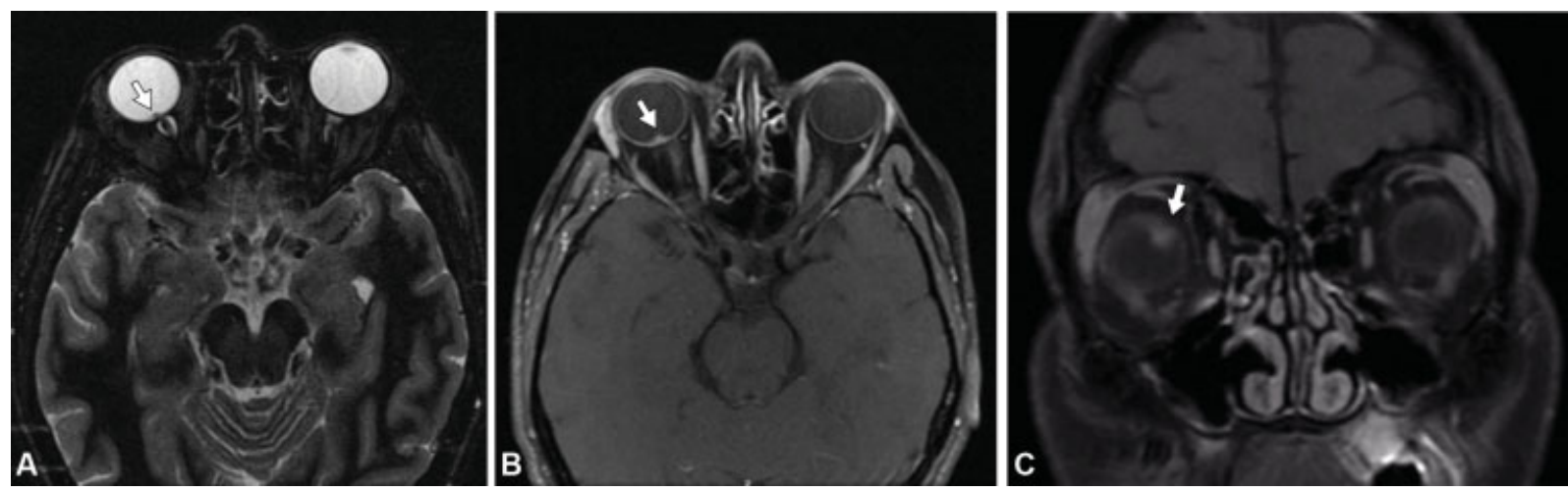

Fig. 1. RM de órbitas en planos axiales y coronales de paciente con diagnóstico de neuroretinitis por $B$. Henseleae. En (A),secuencia ponderada en STIR que muestra irregularidad en polo posterior del globo ocular con área focal hipointensa (flecha). Tras la administración de contraste endovenoso en la secuencia ponderada en T1 con saturación grasa (B y C) se observa realce focal en la unión del nervio óptico con el globo ocular (flecha).

received January 9, 2019

accepted

April 2, 2020
DOI https://doi.org/

10.1055/s-0040-1712141. ISSN 1852-9992.
Copyright @ $\odot$ 2020, Sociedad Argentina de Radiología. Publicado por Thieme Revinter Publicações Ltda., Rio de Janeiro, Brazil. Todos los derechos reservados.

\section{License terms}

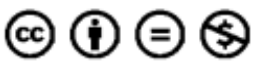



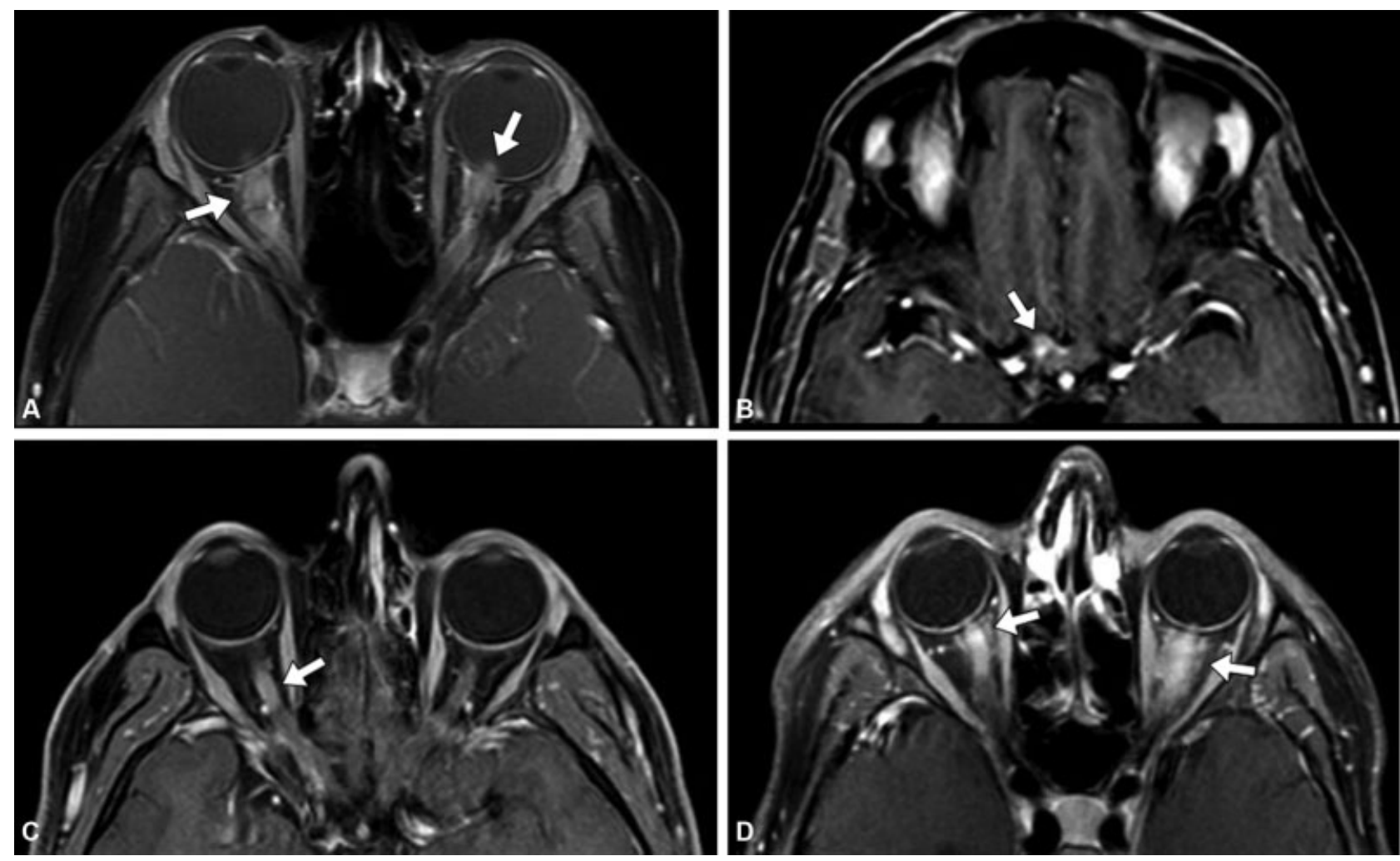

Fig. 2. RM de órbitas de diferentes pacientes con diagnósticos de entidades desmielinizante en plano axial ponderado en T1 con saturación grasa luego de la administración de contraste endovenoso. En (A), paciente con diagnóstico de Anti-MOG, donde se observa extenso realce bilateral y perineural de ambos nervios ópticos (flecha). En (B), paciente con diagnóstico NMO que evidencia realce del segmento intracraneal y quiasmático del lado derecho (flecha). En (C), paciente con diagnóstico de EM que demuestra realce del nervio óptico derecho en su segmento intraorbitario (flecha). En (D), paciente con diagnóstico de neuritis óptica idiopática con realce perineural de ambos nervios ópticos (flecha).

epicentro en su unión con el globo ocular (Schmalfuss y col., ${ }^{9}$ mostraron una especificad del $98 \%$ de ese hallazgo). La neuroretinitis por $B$. Henselae suele tener un curso clínico favorable y autolimitado, presentando, la mayoría de los pacientes, recuperación completa de la agudeza visual en el transcurso de semanas a meses.

En el diagnóstico diferencial de la neuroretinitis por $B$. Henseleae se debe tener en cuenta principalmente la neuritis óptica de etiología desmielinizante como la producida en contexto de esclerosis múltiple (EM), neuromielitis óptica (NMO), anticuerpos contra la glicoproteína de mielinaoligodendrocitos (anti-MOG) y encefalomielitis aguda diseminada (ADEM), entidades que por lo general presentan cambios inflamatorios de mayor extensión y en segmentos posteriores del nervio óptico. ${ }^{10,11}$ Además, esas patologías, en caso de presentar compromiso del segmento intraocular, generalmente se asocian a realce de segmentos posteriores (Fig. 2) a diferencia del realce focal característico de la neuroretinitis por $B$. Henseleae. También se deben tener en cuenta otras causas de neuroretinis que igualmente deben considerarse en el diagnóstico diferencial, entre ellas enfermedades infecciosas o inflamatorias como la toxoplasmosis, toxocariasis, tuberculosis, sífilis, enfermedad de Lyme, rickettsiosis, sarcoidosis, enfermedad de Behçet. ${ }^{12}$ Por otro lado, debemos considerar que existen condiciones clínicas que pueden confundirse con el diagnóstico de neuroretinitis por causar edema de papila y estrella macular. Entre ellas se encuentran la hipertensión arterial, la diabetes mellitus, la hipertensión endocraneana, la oclusión de rama venosa de la retina y la neuropatía óptica isquémica anterior. ${ }^{13}$

Responsabilidades éticas

Protección de personas y animales. Los autores declaran que, para esta investigación, no se han realizado experimentos en seres humanos ni en animales.

Confidencialidad de los datos. Los autores declaran que han seguido los protocolos de su centro de trabajo sobre la publicación de datos de pacientes.

Derecho a la privacidad y consentimiento informado. Los autores declaran que en este artículo no aparecen datos de pacientes.

\section{Conflicto de Intereses}

Los autores del trabajo declaran no tener ningún conflicto de intereses, con excepción del Dr. Hernández Pinzón que declara como posible conflicto de interés ser miembro del Comité Editorial de la RAR. 


\section{Bibliografía}

1 Kerkhoff FT, Bergmans AM, van Der Zee A, Rothova A. Demonstration of Bartonella grahamii DNA in ocular fluids of a patient with neuroretinitis. J Clin Microbiol. 1999;37(12):4034-4038

2 Accorinti M. Ocular bartonellosis. Int J Med Sci. 2009;6(03): 131-132

3 Massei F, Gori L, Macchia P, Maggiore G. The expanded spectrum of bartonellosis in children. Infect Dis Clin North Am. 2005;19 (03):691-711

4 Mabra D, Yeh S, Shantha JG. Ocular manifestations of bartonellosis. Curr Opin Ophthalmol. 2018;29(06):582-587

5 Carithers HA. Cat-scratch disease. An overview based on a study of 1,200 patients. Am J Dis Child. 1985;139(11):1124-1133

6 Cunningham ET, Koehler JE. Ocular bartonellosis. Am J Ophthalmol. 2000;130(03):340-349

7 Welschen Ddel V. Neurorretinitis por Bartonellahenselae: presentación de un caso y revisión de la literatura. Rev Mex Oftalmol. 2016;90(05):235-241
8 Mafee MF. Ocular manifestations of cat-scratch disease: role of MR imaging. AJNR Am J Neuroradiol. 2005;26(06): 1303-1304

9 Schmalfuss IM, Dean CW, Sistrom C, Bhatti MT. Optic neuropathy secondary to cat scratch disease: distinguishing MR imaging features from other types of optic neuropathies. AJNR Am J Neuroradiol. 2005;26(06):1310-1316

10 Toosy AT, Mason DF, Miller DH. Optic neuritis. Lancet Neurol. 2014;13(01):83-99

11 Reddy AK, Morriss MC, Ostrow GI, Stass-Isern M, Olitsky SE, Lowe LH. Utility of MR imaging in cat-scratch neuroretinitis. Pediatr Radiol. 2007;37(08):840-843

12 Ksiaa I, Abroug N, Mahmoud A, Zina S, Hedayatfar A, Attia S, et al. Update on Bartonella neuroretinitis. J Curr Ophthalmol. 2019;31 (03):254-261

13 Kahloun R, Khairallah-Ksiaa I, Abroug N, Mahmoud A, Ben Yahia S, Zaouali S, et al. Final Diagnosis in Patients Referred with a Diagnosis of Neuroretinitis. Neuroophthalmology. 2015;39(06):266-270 